\title{
Vasopressin and the Regulation of Thirst
}

\author{
Daniel G. Bichet \\ University of Montreal and Nephrology Service, Research Center, Hôpital du Sacré-Coeur de Montreal, \\ Montreal, QC, Canada
}

\section{Keywords}

Thirst - Vasopressin - Subfornical organ - Median preoptic nucleus - Organum vasculosum of the lamina terminalis . Anticipatory signals · Aversive state · Sodium x .

Angiotensin II - Water taste receptors

\begin{abstract}
Recent experiments using optogenetic tools allow the identification and functional analysis of thirst neurons and vasopressin producing neurons. Two major advances provide a detailed anatomy of taste for water and arginine-vasopressin (AVP) release: (1) thirst and AVP release are regulated not only by the classical homeostatic, intero-sensory plasma osmolality negative feedback, but also by novel, extero-sensory, anticipatory signals. These anticipatory signals for thirst and vasopressin release converge on the same homeostatic neurons of circumventricular organs that monitor the composition of the blood; (2) acid-sensing taste receptor cells (which express polycystic kidney disease 2-like 1 protein) on the tongue that were previously suggested as the sour taste sensors also mediate taste responses to water. The tongue has a taste for water. The median preoptic nucleus (MnPO)
\end{abstract}

\begin{tabular}{ll}
\hline KARGER & ( 2018 The Author(s) \\
& Published by S. Karger AG, Basel Openger \\
E-Mail karger@karger.com & This article is licensed under the Creative Commons Attribution- \\
www.karger.com/anm & NonCommercial-NoDerivatives 4.0 International License (CC BY- \\
NC-ND) (http://www.karger.com/Services/OpenAccessLicense). \\
Usage and distribution for commercial purposes as well as any dis- \\
tribution of modified material requires written permission.
\end{tabular}

of the hypothalamus could integrate multiple thirst-generating stimuli including cardiopulmonary signals, osmolality, angiotensin II, oropharyngeal and gastric signals, the latter possibly representing anticipatory signals. Dehydration is aversive and $\mathrm{MnPO}$ neuron activity is proportional to the intensity of this aversive state.

C 2018 The Author(s)

Published by S. Karger AG, Basel

In a previous Annals of Nutrition and Metabolism [1], I reviewed recent cellular and optogenetic animal experiments demonstrating that brain circumventricular organ sensors reacting to osmotic pressure and angiotensin II (AII) subserve the genesis of thirst, volume regulation, and behavioral effects of thirst avoidance.

I am now describing a detailed wiring map for thirst (i.e., including anticipatory signals for thirst and vasopressin release converging on the same homeostatic neurons), circumventricular organs that monitor the composition of the blood [2], and the identification of specific water receptor taste cells [3]. The median preoptic nucleus (MnPO) of the hypothalamus could integrate multiple thirst-generating stimuli $[4,5]$. These new data from op- 
Fig. 1. Anticipatory thirst and central control of volemia. SFO, subfornical organ; $\mathrm{MnPO}$, median preoptic nucleus; PVH, paraventricular nucleus; OVLT, organum vasculosum of the lamina terminalis; SON, supraoptic nucleus; AII, angiotensin II.

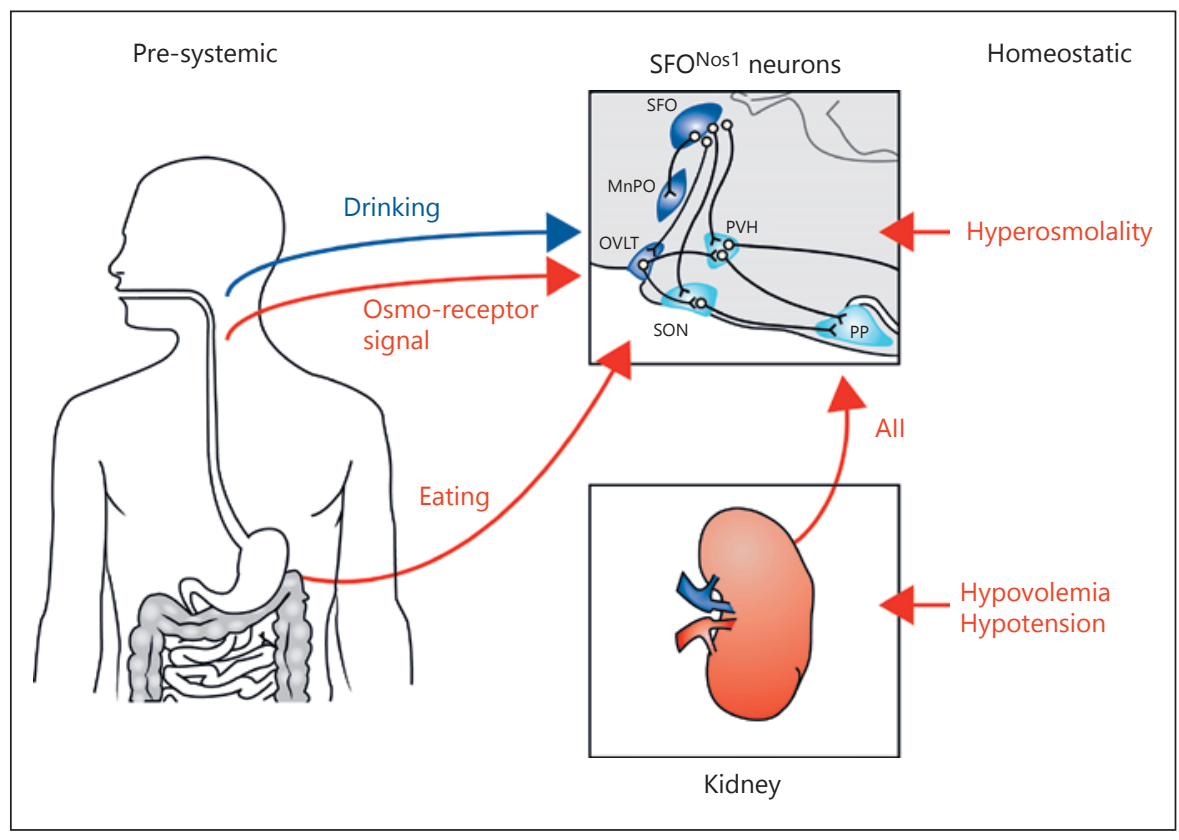

togenetic experiments done in rodents explain findings obtained in humans using blood oxygen level-dependent (BOLD) signals demonstrating that the increase in the lamina terminalis (LT) BOLD signal observed during an infusion of hypertonic saline is rapidly decreased after water intake well before any water absorption in blood [18].

\section{Intero-Sensory and Extero-Sensory Regulation of Thirst and Vasopressin Release (Fig. 1)}

Intero-sensory stimuli: perception of osmolality (increased with intracellular dehydration) and, through AII, plasma volume and perfusion pressure (both decreased with extracellular dehydration). Importance of sodium $x$ (Nax) signals to distinguish water depleted from salt depleted conditions.

(a) Osmoreceptor cells of the subfornical organ (SFO) bear AII receptors and project to vasopressin producing cells in the supraoptic nucleus (SON) and paraventricular nucleus (PVH).

Homeostatic neurons of the SFO are osmoreceptor cells and, through their AII receptors, perceive plasma volume and vascular perfusion pressure. This is the classical intero-sensory regulation responsible for conscious thirst perception, since these neurons project to the anterior cingulate cortex [6]. These SFO neurons are also responsible for vasopressin release since they project to vasopressin producing neurons in the SON and PVH [7]. Extracellular fluid hyperosmolality stimulates the sensation of thirst to promote water intake and the release of vasopressin that will enhance water reabsorption in the kidney. By contrast, extracellular fluid hypo-osmolality suppresses basal vasopressin secretion. Thirst and vasopressin release appear, thus far, as a purely homeostatic response to deviations in intero-sensory stimuli: blood osmolality, pressure, or volume.

(b) Two types of AII receptor type 1a-positive excitatory neurons exist in the subfornical organ. Nax is expressed in glial cells surrounding SFO cells and serves to distinguish water depleted from salt depleted conditions, both stimulated by AII.

AII drives both thirst and salt appetite. Matsuda et al. $[8,9]$ showed that thirst and salt appetite are driven by 2 distinct groups of AII (receptor type 1a-positive excitatory) neurons in the subfornical organ. Neurons projecting to the organum vasculosum LT control water intake, while those projecting to the ventral part of the bed nucleus of the stria terminalis control salt intake. Thirstdriving neurons are suppressed under sodium-depleted conditions. In contrast, the salt appetite-driving neurons are suppressed under dehydrated conditions through activation of GABAergic neurons by Nax signals [10]. These distinct mechanisms in the subfornical organ may underlie the selective intakes of water and/or salt and may contribute to body fluid homeostasis (Fig. 2). 
Fig. 2. The anatomy for taste of water. SFO, subfornical organ; MnPO, median preoptic nucleus; PVH, paraventricular nucleus; OVLT, organum vasculosum of the lamina terminalis; SON, supraoptic nucleus; BNSTvl, bed nucleus of the lamina terminalis; SCN, suprachiasmatic nucleus.

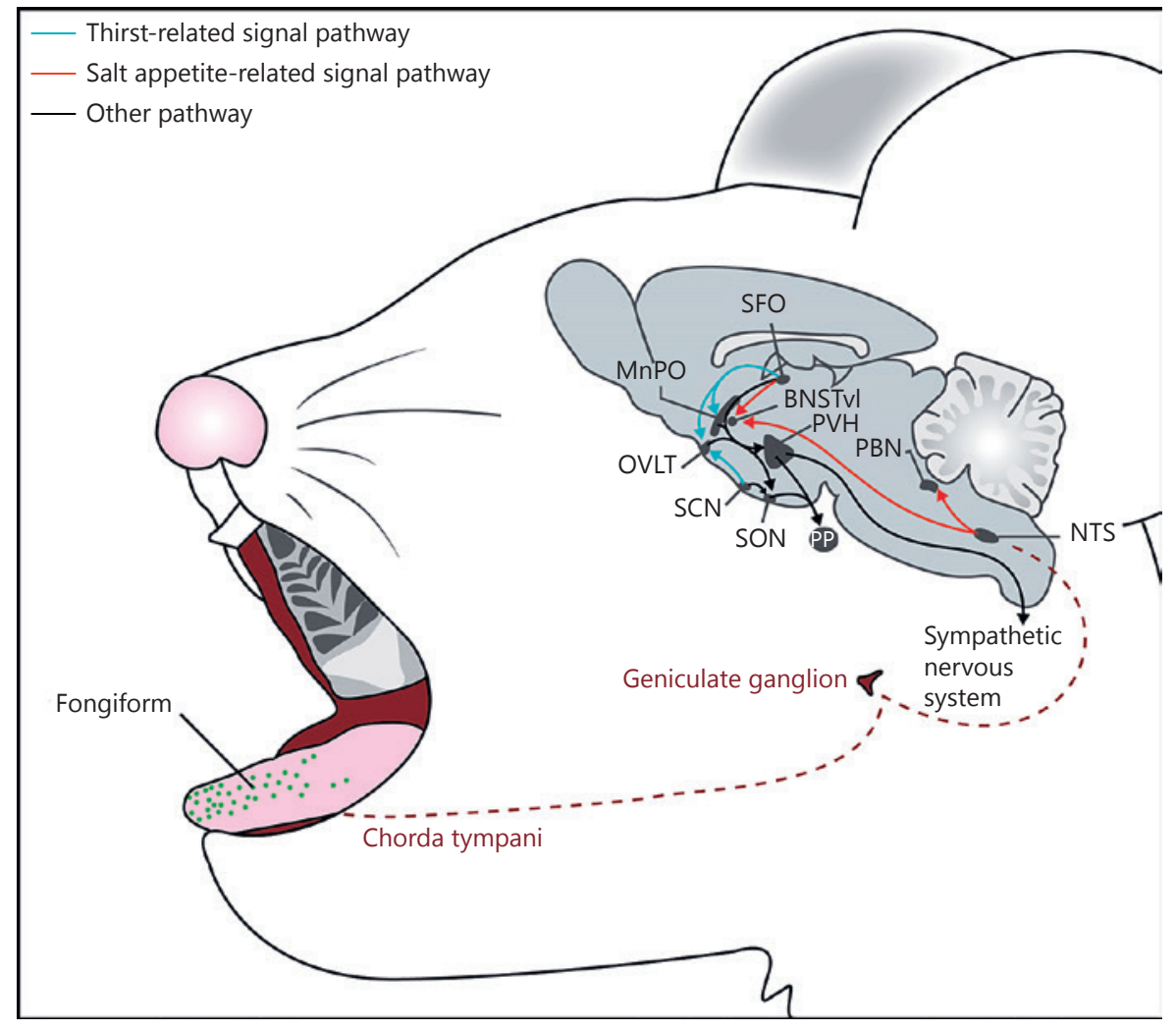

The techniques used in the 1960s and 1970s to describe these intero-sensory stimuli lacked the ability to track thirst neurons of the LT and vasopressin neurons projecting to the posterior pituitary in real time in conscious animals, and so could not assess extero-sensory information regulating these processes[11].

\section{Extero-Sensory Stimulation Anticipates Thirst Stimulation and Vasopressin Release: Importance of Taste Water Receptors}

Recent experiments using optogenetic tools [12] in awake animals demonstrate that a substantial fraction of normal drinking behavior and vasopressin release are not regulated directly by changes in the blood. Instead, this behavior appears to anticipate homeostatic changes before they occur [13]. Anticipatory signals for thirst and vasopressin release converge on the same homeostatic neurons, subfornical organ neurons, which monitor the tonicity of blood $[14,15]$. The activity of subfornical organ excitatory neurons (SFO ${ }^{\text {Nos1 }}$; Fig. 1) $[1,7,16$, 17], activated by water restriction, rapidly return to baseline after water access, well before any measurable change in plasma osmolality occurs [14]. This rapid anticipatory response to drinking has been suggested by blood oxygen level-dependent (i.e., functional magnetic resonance imaging BOLD signal) measurements during thirst stimulation in humans. The BOLD signal from the anterior cingulate cortex area, known to be responsible for the conscious perception of thirst, decreased rapidly after water consumption, well before any systemic absorption of water [18]. There is a delay of approximately $10 \mathrm{~min}$ [19] between the ingestion of water and its full absorption into the bloodstream. These new data explain how drinking can quench thirst within seconds, long before the ingested water alters blood volume or osmolality. The rapid anticipatory response to drinking has at least 2 components: an immediate signal that tracks fluid ingestion, and a delayed signal that reports fluid tonicity, possibly generated by an esophageal or gastric osmosensor.

The recently described water taste receptor cells could be this immediate signal tracking fluid ingestion [3]. Oka et al. [7] at the California Institute of Technology in Pasadena demonstrated that the tongue has a taste for water: they found that applying deionized water to the tongues of mice caused specific taste nerves to fire. This was due 
to a change in the $\mathrm{pH}$ of the saliva as it was diluted by the water. The team engineered mice to make their sour taste (acid-sensing) receptors sensitive to light. In response to light stimulation, mice continuously tried to drink from an empty bottle - but only if they had previously been deprived of water. This suggests that the activation of these tongue cells drives drinking behavior when an animal is thirsty. Mice lacking acid-sensing taste receptors lost the ability to distinguish water from non-aqueous liquids such as oil.

Esophageal and/or gastric sensors could also convey organ-specific information via the sensory vagus nerve [20], in a manner similar to the concept of appetite control suggested by Andermann and Lowell [21]. This involves feedforward control of hypothalamic activity via external cues regarding mealtimes, food, and water availability; this activity regulates feeding and water absorption to prevent future homeostatic perturbations. These rapid, bidirectional feedback and feedforward predictive signals are ubiquitous; they have been described in the control of feeding, water circuits [21], and in the cardiovascular system [22]. As commented by Andermann and Lowell [21] citing the work of Carpenter [23], "the whole of the brain may be regarded as a way of helping the hypothalamus to do a better job, by making better predictions of what is going to happen next, and what is likely to follow from one course of action rather than another."

From a Darwinian point of view, the rapid, volumetrically exact intake of water (i.e., consequent upon thirst or a salt solution in the case of sodium depletion), carries high survival advantage. It permits animals to go to a water or salt source, to rapidly correct the deficit and leave the place, reducing their exposure to predators that have learned to wait there [24].

\section{Coordination of Eating, Drinking, and Vasopressin Release}

Eating increases the need for water for 2 reasons: (1) there is a need to replace the fluid utilized for swallowing (saliva) and digestion (water diverted from the circulation into the gastrointestinal tract); and (2) to counteract the increase in blood osmolality caused by the absorption of salts and other osmoles from food. As described recently in a review on thirst, [13] anticipatory signals about ongoing food ingestion are communicated to the LT by multiple mechanisms. For example, somatosensory signals from the oral cavity report on food swallowing or its effects on the saliva. Further, several hormones associated with eating and satiety have been proposed to modulate thirst neurons and vasopressin release, including amylin, cholecystokinin, ghrelin, histamines, insulin, and leptin. Some of these hormones might be elevated in patients with diabetes mellitus and may explain their high vasopressin plasma concentration [25].

The responses to drinking and feeding are bidirectional, yet asymmetric. Using electrophysiological recordings (i.e., of genetically identified SON pituitaryprojecting vasopressin $\left(\mathrm{VP}_{\mathrm{pp}}\right)$ neurons in water-restricted mice), Mandelblat-Cerf et al. [15] observed rapid decreases in neuron activity within seconds of presentation of cues signaling water availability, prior to water ingestion. In contrast, ingestion of dry food - a hyperosmotic challenge - elicited rapid increases in $\mathrm{VP}_{\mathrm{pp}}$ neuron activity prior to any increase of plasma osmolality. If prandial thirst is not quenched by drinking, then further food consumption is reduced; known as dehydration-induced anorexia, this phenomenon could be observed in young patients with congenital nephrogenic diabetes insipidus [26]. Altogether, these new data explain the speed of thirst satiation, the fact that oral cooling is thirstquenching, and the widespread coordination of eating, drinking, and vasopressin release. Feedforward signals for thirst do not work in parallel and or apart from homeostatic thirst neurons, but instead work through homeostatic neurons.

Anticipatory, feedforward signals for thirst and vasopressin release converge on the same homeostatic neurons detecting the feedback signals of osmolality and circulating AII as shown in Figure 1. The anticipatory signals explain the speed of thirst satiation and the widespread coordination of eating, drinking, and vasopressin release (modified figure from [14].

An illustration of new data described in this review on the cell type-specific neural circuits that underlie thirst and fluid homeostasis in the mouse brain (modified from [2]; [27], and from Gizowski and Bourque [5]) is shown in Figure 2. The LT consists of 2 sensory circumventricular organs (the SFO and organum vasculosum of the LT [OVLT]) and an integrative structure (the MnPO). Information about plasma osmolality, volume, and pressure enters the LT through specialized interoceptive neurons in the SFO and OVLT, some of which are intrinsically osmosensitive and AII-sensitive (for example, SFOGLUT neurons). The LT nuclei communicate with each other through an extensive network of bidirectional projections that has not yet been fully mapped with cell-type specific- 
ity. Other pathways: (1) outside the LT, SFO ${ }^{\text {GLUT }}$ neurons project to the $\mathrm{PVH}, \mathrm{SON}$ and ventral bed nucleus of the LT (BNSTvl); (2) projections from the MnPO and OVLT to the PVH and SON are well established; (3) argininevasopressin (AVP) neurons in the suprachiasmatic nucleus (SCN ${ }^{\mathrm{AVP}}$ neurons) project to the OVLT and SON to mediate circadian regulation of thirst and AVP secretion, respectively.

Water taste receptors on fungiform cells of the tongue drive drinking behavior. Information about plasma sodium enters the circuit through specialized aldosterone- sensitive neurons in the nucleus of the solitary tract (NTS) that express $11 \beta$-hydroxysteroid dehydrogenase type 2 (NTSHSD2 neurons), which promote salt appetite and project to the pre-locus coeruleus (pre-LC), parabrachial nucleus, and BNSTvl.

\section{Disclosure Statement}

D.G.B. received travel expenses and registration fee from Danone Nutricia Research to attend the 2017 Hydration for Health Scientific Conference.

\section{References}

1 Bichet DG: Vasopressin at central levels and consequences of dehydration. Ann Nutr Metab 2016;68(suppl 2):19-23.

2 Zimmerman CA, Leib DE, Knight ZA: Neural circuits underlying thirst and fluid homeostasis. Nat Rev Neurosci 2017;18:459-469.

3 Zocchi D, Wennemuth G, Oka Y: The cellular mechanism for water detection in the mammalian taste system. Nat Neurosci 2017;20: 927-933.

4 Allen WE, DeNardo LA, Chen MZ, Liu CD, Loh KM, Fenno LE, Ramakrishnan C, Deisseroth K, Luo L: Thirst-associated preoptic neurons encode an aversive motivational drive. Science 2017;357:1149-1155.

5 Gizowski C, Bourque CW: Neurons that drive and quench thirst. Science 2017;357:10921093.

6 Hollis JH, McKinley MJ, D’Souza M, Kampe J, Oldfield BJ: The trajectory of sensory pathways from the lamina terminalis to the insular and cingulate cortex: a neuroanatomical framework for the generation of thirst. Am J Physiol Regul Integr Comp Physiol 2008; 294:R1390-R1401.

7 Oka Y, Ye M, Zuker CS: Thirst driving and suppressing signals encoded by distinct neural populations in the brain. Nature 2015;520: 349-352.

8 Matsuda T, Hiyama TY, Niimura F, Matsusaka T, Fukamizu A, Kobayashi K, Kobayashi K, Noda M: Erratum: Distinct neural mechanisms for the control of thirst and salt appetite in the subfornical organ. Nat Neurosci 2017; 20:230-241.

9 Matsuda T, Hiyama TY, Niimura F, Matsusaka T, Fukamizu A, Kobayashi K, Kobayashi K, Noda M: Erratum: Distinct neural mecha- nisms for the control of thirst and salt appetite in the subfornical organ. Nat Neurosci 2017; 20:896.

10 Hiyama TY, Noda M: Sodium sensing in the subfornical organ and body-fluid homeostasis. Neurosci Res 2016;113:1-11.

11 Watts AG: Great expectations: anticipatory control of magnocellular vasopressin neurons. Neuron 2017;93:1-2.

12 Deisseroth K, Schnitzer MJ: Engineering approaches to illuminating brain structure and dynamics. Neuron 2013;80:568-577.

13 Leib DE, Zimmerman CA, Knight ZA: Thirst. Curr Biol 2016;26:R1260-R1265.

14 Zimmerman CA, Lin YC, Leib DE, Guo L, Huey EL, Daly GE, Chen Y, Knight ZA: Thirst neurons anticipate the homeostatic consequences of eating and drinking. Nature 2016; 537:680-684.

15 Mandelblat-Cerf Y, Kim A, Burgess CR, Subramanian S, Tannous BA, Lowell BB, Andermann ML: Bidirectional anticipation of future osmotic challenges by vasopressin neurons. Neuron 2017;93:57-65.

16 Son SJ, Filosa JA, Potapenko ES, Biancardi VC, Zheng H, Patel KP, Tobin VA, Ludwig M, Stern JE: Dendritic peptide release mediates interpopulation crosstalk between neurosecretory and preautonomic networks. Neuron 2013;78:1036-1049.

17 Zaelzer C, Hua P, Prager-Khoutorsky M, Ciura S, Voisin DL, Liedtke W, Bourque CW: $\triangle \mathrm{N}$-TRPV1: A molecular co-detector of body temperature and osmotic stress. Cell Rep 2015;13:23-30.

18 Egan G, Silk T, Zamarripa F, Williams J, Federico P, Cunnington R, Carabott L, BlairWest J, Shade R, McKinley M, Farrell M, Lan- caster J, Jackson G, Fox P, Denton D: Neural correlates of the emergence of consciousness of thirst. Proc Natl Acad Sci U S A 2003;100: 15241-15246.

19 Bourque CW: Central mechanisms of osmosensation and systemic osmoregulation. Nat Rev Neurosci 2008;9:519-531.

20 Williams EK, Chang RB, Strochlic DE, Umans BD, Lowell BB, Liberles SD: Sensory neurons that detect stretch and nutrients in the digestive system. Cell 2016;166:209221.

21 Andermann ML, Lowell BB: Toward a wiring diagram understanding of appetite control. Neuron 2017;95:757-778.

22 Dampney RA: Central neural control of the cardiovascular system: current perspectives. Adv Physiol Educ 2016;40:283-296.

23 Carpenter RH:Homeostasis:a plea for a unified approach. Adv Physiol Educ 2004;28:180-187.

24 Saker P, Farrell MJ, Adib FR, Egan GF, McKinley MJ, Denton DA: Regional brain responses associated with drinking water during thirst and after its satiation. Proc Natl Acad Sci U S A 2014;111:53795384.

25 Kageyama K, Yamagata S, Akimoto K, Sugiyama A, Murasawa S, Suda T: Action of glucagon-like peptide 1 and glucose levels on corticotropin-releasing factor and vasopressin gene expression in rat hypothalamic $4 \mathrm{~b}$ cells. Mol Cell Endocrinol 2012;362:221-226.

26 Bockenhauer D, Bichet DG: Nephrogenic diabetes insipidus. Curr Opin Pediatr 2017;29: 199-205.

27 Yarmolinsky DA, Zuker CS, Ryba NJ: Common sense about taste: from mammals to insects. Cell 2009;139:234-244. 